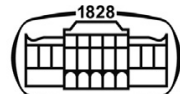

AKADÉMIAI KIADÓ

Journal of Behavioral Addictions

9 (2020) 3, 572-588

D01:

$10.1556 / 2006.2020 .00058$

(c) 2020 The Author(s)

\section{REVIEW ARTICLE}

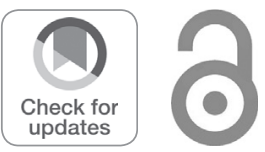

\title{
Identifying individuals in need of help for their uncontrolled gaming: A narrative review of concerns and comments regarding gaming disorder diagnostic criteria
}

\author{
CHIH-HUNG KO ${ }^{1,2,3 *}$ @e, ORSOLYA KIRÁLY ${ }^{4}$, \\ ZSOLT DEMETROVICS ${ }^{4}$, YUN-MING CHANG ${ }^{5}$ and \\ JU-YU YEN ${ }^{1,3,6}$
}

\footnotetext{
${ }^{1}$ Department of Psychiatry, Kaohsiung Medical University Hospital, Kaohsiung Medical University, 100 Tzyou 1st Rd., 807, Kaohsiung City, Taiwan

${ }^{2}$ Department of Psychiatry, Kaohsiung Municipal Siaogang Hospital, Kaohsiung Medical University, 482 San-Ming Rd., 812, Kaohsiung City, Taiwan

${ }^{3}$ Department of Psychiatry, Faculty of Medicine, College of Medicine, Kaohsiung Medical University, 100 Shi-Chuan 1st Rd., 807, Kaohsiung City, Taiwan

${ }^{4}$ Institute of Psychology, ELTE Eötvös Loránd University, Budapest, Hungary

${ }^{5}$ Department of Psychology, Minnan Normal University, China

${ }^{6}$ Department of Psychiatry, Kaohsiung Municipal Ta-Tung Hospital, Kaohsiung Medical University, Kaohsiung City, 812, Taiwan
}

Received: April 2, $2020 \bullet$ Revised manuscript received: July 28, $2020 \bullet$ Accepted: August 21, 2020

Published online: October 3, 2020

\begin{abstract}
Objective: In 2013, the Diagnostic and Statistical Manual of Mental Disorders, Fifth Edition (DSM-5) included the diagnostic criteria of Internet gaming disorder (IGD). Then, in 2019, the 11th Revision of the International Classification of Diseases (ICD-11) categorized gaming disorder (GD) as an addictive disorder. This review aimed to review the raised concerns, debate, and research of IGD or GD criteria and provide suggestions to resolve them. Methods: A narrative review was conducted, and PubMed was searched for articles mentioning concerns and research on the DSM-5 criteria for IGD, ICD-11 criteria for GD, or criteria for other synonyms, such as problematic gaming or gaming addiction. A total of 107 articles were identified. Results: Concerns were organized into three categories: conceptual framework, moral panic, and diagnostic validity. Most argumentations supported the proposition that GD and other substance use disorders have similar presentations. A clear definition of GD and adequate public education could prevent rather than exacerbate moral panic. Several researchers reported concerns regarding the nosology, diagnostic validity, and wording of each criterion. However, the threshold, five of the nine criteria with impaired function, demonstrated adequate validity in interview studies. Conclusion: The current findings support the addiction framework, functional impairment, and validity of the GD criteria. However, further prospective, experimental, and clinical studies validating these findings are warranted. Moreover, an integrative review or debate conference could contribute to the organization of the available results and concept development. Aggregating adequate scientific information could allay or resolve concerns related to the diagnosis of GD.
\end{abstract}

\section{KEYWORDS}

DSM-5, ICD-11, Internet Gaming Disorder, Gaming Disorder, validity, criteria
*Corresponding author.

E-mail: chihhungko@gmail.com 


\section{INTRODUCTION}

Video gaming has become one of the most popular recreational activities, with approximately 2.5 billion people playing games worldwide (WePC, 2019). Heathy gaming may have important benefits for education, training, and skills development (Cade \& Gates, 2017). However, the powerful motivational pull of gaming might cause some vulnerable individuals to lose control over their gaming behavior. Although the Diagnostic and Statistical Manual of Mental Disorders, Fifth Edition (DSM-5) does not include Internet gaming disorder (IGD) as an official diagnosis, it suggests diagnostic criteria for IGD in Section III (Emerging measures and models) and recommends further evaluation (American Psychiatric Association [APA], 2013; Griffiths, King, \& Demetrovics, 2014), based on the available scientific evidence and the potential for excessive gaming to have major negative effects on mental health (Petry et al., 2014b).

In 2019, the International Classification of Diseases, 11th Revision (ICD-11) classified gaming disorder (GD) as an addictive disorder (World Health Organization [WHO], 2019). Scholars have raised several concerns regarding the appropriateness and validity of these diagnostic criteria (Aarseth et al., 2017). However, reliable diagnostic criteria are required to explore the mental symptoms of GD and enable the development of effective treatment plans for individuals who require professional help (King et al., 2018; King et al., 2019; Kuss, Griffiths, \& Pontes, 2017a). The present review organizes the various concerns, recommendations, and findings regarding diagnostic criteria to help mental health professionals understand the conflicting perspectives on this topic. Furthermore, suggestions are provided for future studies to resolve or allay the concerns and provide a more rigorous assessment of patients.

\section{BACKGROUND}

\section{The diagnostic criteria of IGD in the DSM-5}

IGD in DSM-5 can be characterized by persistent gaming that leads to clinically significant impairment or distress as indicated by the presence of at least five of the nine criteria in a 12-month peri od. The nine criteria are 1) preoccupation, 2) withdrawal, 3) tolerance, 4) unsuccessful attempts to control, 5) loss of interest in previous forms of entertainment, 6) continued excessive gaming despite psychological problems, 7) engaging in deceptive behavior, 8) escape by using gaming, and 9) jeopardizing or losing a significant relationship, job, or educational or career opportunity because of gaming.

Several studies have evaluated the DSM criteria to determine their validity (Király et al., 2017; Ko et al., 2014; Ko, Lin, Lin, \& Yen, 2019; Koo, Han, Park, \& Kwon, 2017; Müller, Beutel, Dreier, \& Wölfling, 2019). These studies have supported the validity of most criteria and the cut-off point in DSM-5 (i.e., five of nine criteria) in identifying individuals with IGD. However, extensive concerns regarding the DSM5 criteria have also been raised in the literature.

\section{The ICD-11 diagnostic criteria for GD and hazardous gaming}

ICD-11 included GD as an addictive disorder in 2019 (WHO, 2019). The GD criteria apply to both online and offline gaming because of the similarities in addictions to online and offline games (Kuss et al., 2017a). The DSM-5 IGD criteria could also be applied to offline games (APA, 2013; Petry et al., 2014a). However, the term "Internet gaming disorder" may cause confusion (Király, Griffiths, \& Demetrovics, 2015) and prevent the application of the criteria to offline games.

\section{The diagnostic criteria of GD in the ICD-11}

The criteria GD are as follows: 1) impaired control over gaming, 2) increased priority given to gaming to the extent that gaming tasks take precedence over other activities, and 3) continued gaming despite negative consequences and the behaviour pattern resulting in marked impairment to function over a period longer than 12 months.

\section{The diagnostic criteria of hazardous gaming}

Hazardous gaming is evident by a pattern of gaming that increases the risk of harmful physical or mental health consequences but has not yet reached the level to be diagnosed with GD.

\section{Aims}

Griffiths et al. (2016) have expressed the need for a consensus on the DSM-5 IGD criteria. Furthermore, Kuss et al. (2017a) reviewed concerns expressed regarding the DSM-5 IGD criteria. They proposed some possible means by which to resolve these concerns. However, other scholars have raised further concerns regarding those proposals (van Rooij et al., 2018). These proposals and concerns warrant further research to achieve clarity and resolution. The present narrative review aimed to collect, summarize, and discuss the various concerns, debate, and research on these diagnostic criteria, using a dimensional approach, to help mental health professionals and scholars organize reasonable solutions to these problems. In this review, the terms "Internet gaming disorder" and "gaming disorder" will be used. For consistency reasons, the latter (GD) will be used to represent all the other synonyms (e.g., problematic gaming or gaming addiction) as well, since that is the term with the strongest consensus among scholars at the moment.

\section{METHODS}

The PubMed database was searched for articles mentioning concerns, debate or research on the criteria for GD, including the DSM-5 criteria for IGD and the ICD-11 criteria for GD. The following search algorithm was used: "gaming" in "title" AND "criteria," "concerns," "debate," or "consensus" in the "abstract/title." PubMed was selected 
because it contains over 30 million citations for biomedical literature from MEDLINE, life science journals, and online books. Furthermore, the majority of consequential articles are filed in PubMed. In total, 150 articles in PubMed were identified in the period from 2011 to March 2019. Of these, 121 were IGD or GD related. Concerns, debate or research regarding these diagnosing criteria were discussed in 86 of the articles. After the content of these 86 articles (denoted using * in the reference list) was evaluated, another 21 articles (denoted using \# in the reference list) that mentioned concerns regarding the IGD or GD criteria but were not recruited in search strategy in PubMed were identified from the citations of the 86 articles. The concerns and results presented in the 107 articles were then summarized and organized into three categories. Furthermore, suggestions are presented regarding the types of studies that would be necessary to address the concerns.

\section{RESULTS}

\section{Three major dimensions of concern}

Reviewing of the 107 articles revealed that most of the concerns relate to three critical problems: (i) whether GD is an addictive disorder, (ii) the possible public impact of considering GD a mental disorder, and (iii) whether the GD criteria are suitable to identify individuals with problematic gaming that requires further intervention. Therefore, we classified these concerns into three categories: conceptual framework, moral panic, and diagnostic validity (see Tables $1-3$ )

Table 1. Concerns regarding the conceptual framework of the Diagnostic and Statistical Manual of Mental Disorders, Fifth Edition (DSM-5) Internet gaming disorder (IGD) and the International Classification of Diseases, 11th Revision (ICD-11) gaming disorder (GD) criteria

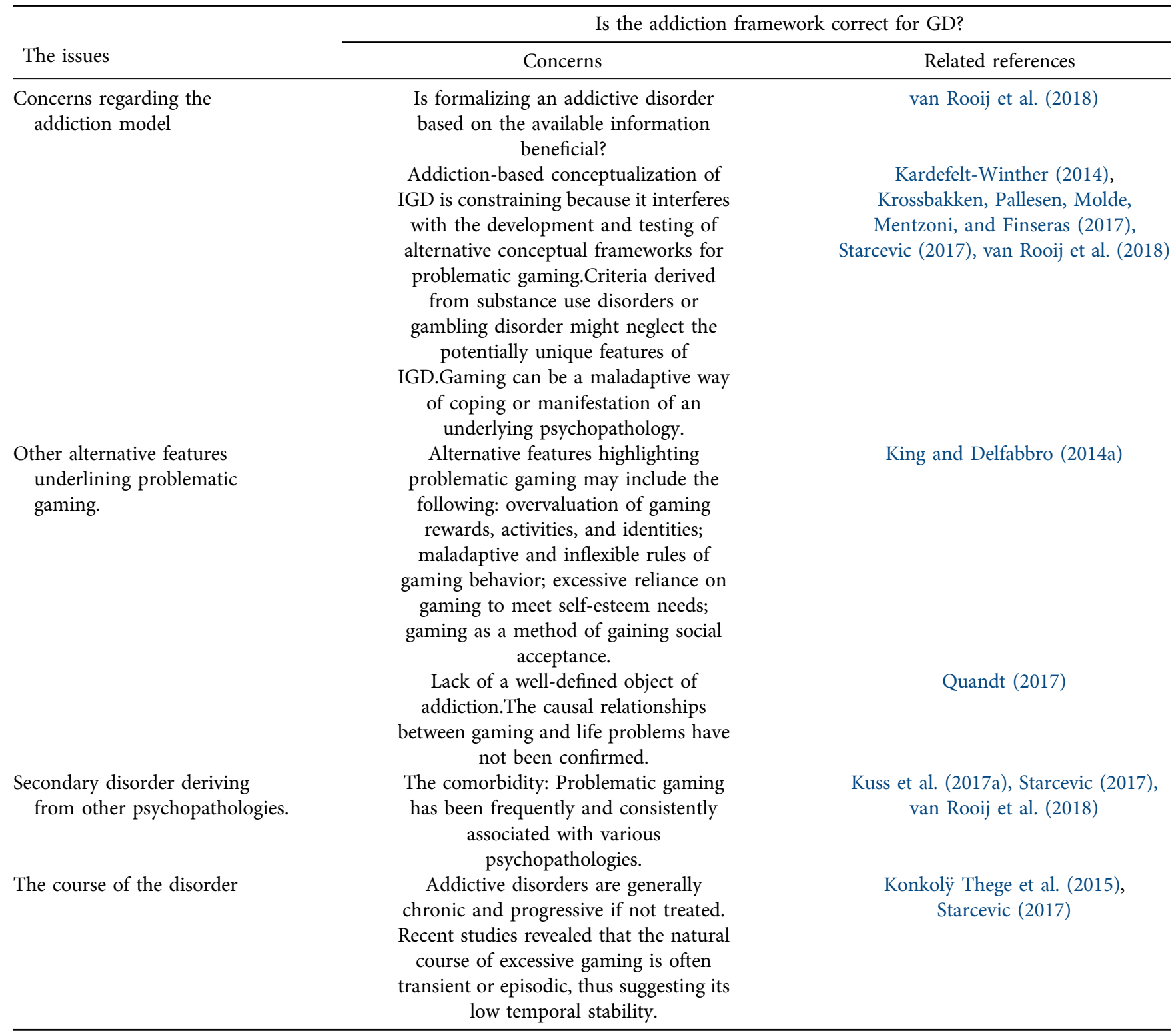


Table 2. Concerns regarding the moral panic effect of the Diagnostic and Statistical Manual of Mental Disorders, Fifth Edition (DSM-5) Internet gaming disorder (IGD) and the International Classification of Diseases, 11th Revision (ICD-11) gaming disorder (GD) criteria and definitions

\begin{tabular}{|c|c|c|}
\hline \multirow[b]{2}{*}{ Topics } & \multicolumn{2}{|c|}{$\begin{array}{l}\text { Diagnosis of gaming disorder may result in a moral panic regarding gaming } \\
\text { behavior in general. }\end{array}$} \\
\hline & Concerns & Related references \\
\hline \multirow[t]{3}{*}{$\begin{array}{l}\text { Premature diagnoses could cause a } \\
\text { moral panic that would limit healthy } \\
\text { gaming behaviors. }\end{array}$} & $\begin{array}{l}\text { First, moral panic is particularly } \\
\text { concerning when addressing the harms } \\
\text { caused by video gaming. Moral panic } \\
\text { could result in the medical community } \\
\text { applying premature diagnoses and } \\
\text { treatment of abundant false-positive } \\
\text { cases, especially among children and } \\
\text { adolescents. Second, research may } \\
\text { remain focused on a confirmatory } \\
\text { approach, rather than on exploration of } \\
\text { the boundaries between normal and } \\
\text { pathological gaming. Third, most } \\
\text { healthy gamers may be negatively } \\
\text { affected. }\end{array}$ & $\begin{array}{c}\text { Markey and Ferguson (2017), van Rooij } \\
\text { et al. (2018), Kardefelt-Winther (2014), } \\
\text { Aarseth et al. (2017) }\end{array}$ \\
\hline & $\begin{array}{l}\text { Gaming behavior differs from substance } \\
\text { abuse behaviors. It is one of the most } \\
\text { popular hobbies among children and } \\
\text { adolescents worldwide and has } \\
\text { numerous healthy and positive } \\
\text { outcomes. }\end{array}$ & Granic, Lobel, \& Engels (2014) \\
\hline & $\begin{array}{l}\text { However, only gaming disorder has } \\
\text { been proposed for ICD-11 inclusion, } \\
\text { with no formal or transparent review of } \\
\text { the evidence quality for any of the } \\
\text { various addictions. }\end{array}$ & van Rooij et al. (2018) \\
\hline \multirow[t]{3}{*}{ Is IGD a real problem? } & $\begin{array}{l}\text { If no patients are identified, a formal } \\
\text { disorder category may not be required. }\end{array}$ & van Rooij et al. (2018) \\
\hline & $\begin{array}{l}\text { Feelings of distress caused by gaming } \\
\text { were reported by only } 0.3 \%-1 \% \text { of the } \\
\text { sample subjects. }\end{array}$ & $\begin{array}{l}\text { Przybylski, Weinstein, and Murayama } \\
\qquad(2017)\end{array}$ \\
\hline & $\begin{array}{l}\text { The social and political effects of } \\
\text { declaring that a social behavior is a } \\
\text { disease are a cause for concern. }\end{array}$ & Quandt (2017) \\
\hline
\end{tabular}

\section{Conceptual framework of GD}

Many scholars have claimed that excessive gaming that causes negative consequences is not necessarily indicative of an addictive disorder (see Table 1). Classification of problematic gaming as an addictive disorder might thus interfere with the development of alternative conceptual frameworks (Starcevic, 2017; van Rooij \& Kardefelt-Winther, 2017). For example, gaming could be a coping strategy for stress (Canale et al., 2019) or secondary to another psychiatric disorder. King \& Delfabbro (2014a) and van Rooij et al. (2018) reported that the underlying cause or alternative cognitive features of problematic gaming behavior, such as coping behavior or overvaluation, should be explored before GD is defined as an addictive disorder.

However, Kuss, Griffiths, and Pontes (2017b) reported that GD is "a maladaptive coping behavior fits perfectly well within an addiction framework." Numerous studies have supported that mechanisms of addictive behavior can be observed in GD, including attention bias (van Holst et al., 2012), risky decision-making (Bailey, West, \& Kuffel, 2013), alteration in executive control (Dong, Liu, Zheng, Du, \& Potenza, 2019), rewarding alteration (Duven, Müller, Beutel, \& Wölfling, 2015), emotional regulation (Yen et al., 2017), and stress vulnerability (Kaess et al., 2017; S. Yu, Mao, \& $\mathrm{Wu}, 2018)$. Two reviews have suggested possible underlying factors, such as cognitive control, emotional regulation, decision-making, and environmental factors, that contribute to GD development and maintenance (Dong \& Potenza, 2014; Kuss, Pontes, \& Griffiths, 2018), in the same manner that they contribute to substance use disorders. Furthermore, studies have demonstrated similarities in comorbidities, such as attention deficit hyperactivity disorder (Pearcy, McEvoy, \& Roberts, 2017; Yen, Liu et al., 2017), depression (Liu et al., 2018; Martín-Fernández et al., 2016), anxiety disorder (González-Bueso et al., 2018; Wang et al., 2017), 
Table 3. Concerns regarding the diagnostic validity of the Diagnostic and Statistical Manual of Mental Disorders, Fifth Edition (DSM-5) Internet gaming disorder (IGD) and the International Classification of Diseases, 11th Revision (ICD-11) gaming disorder (GD) criteria and definitions

\begin{tabular}{lcc}
\hline & Validity of the diagnostic criteria to identify individuals with GD. \\
\cline { 2 - 3 } Topics & Concerns
\end{tabular}

Diagnostic validity

Validity of each criterion Preoccupation

Loss of control

Gaming despite negative consequences

Withdrawal

Tolerance
Further research may indicate that the diagnostic threshold fails to differentiate nondependent from dependent use and that certain criteria do not increase diagnostic accuracy.

Data regarding measures for IGD on predictive validity and interrater reliability is inadequate.

IGD risks pathologizing normal behaviors if numerous symptoms that do not indicate pathology are included. Content validity, construct validity, and face validity should be tested.

The polythetic, nonhierarchical DSM-5 diagnostic criteria for IGD renders the concept of IGD unacceptably heterogeneous.

Intensity and frequency measures are required to represent the pathological threshold of each IGD and GD criteria.

Preoccupation with gaming or feeling upset when an individual cannot participate to the desired extent are not necessarily indicators of pathology.

The cognitive factors related to preoccupation must be clarified.

"Distracted by thoughts on gaming which hinder concentration on work or other important tasks" may be more accurate than "thinking or planning when not playing".

Preoccupation should not be assessed on time alone but also on the cognitive content. "Perceiving gaming as central to their lives" or "whether they could imagine

their lives without gaming" could be considered.

Worse diagnostic accuracy compared with the other IGD criteria.

A desire or intention to stop playing is required.

Cultural bias, rational choice, and age should be considered.

Are the negative consequences short-term or longterm?

The response to an immediate disruption of gaming or prolonged refrainment from gaming ( $\geq 2$ weeks) may not be withdrawal symptoms.

"Over a period of up to 2 days" and "relieved by the ability to play" could be used in evaluating the withdrawal symptoms.

Current evidence on Internet gaming withdrawal is very underdeveloped.

Although current evidence is very underdeveloped, the most consistently reported emotional and behavioral withdrawal symptoms were irritability and restlessness, not physical withdrawal symptoms.

Tolerance could be described as "diminished levels of gaming satisfaction because of prolonged gaming activity".
Dowling (2014)

King, Haagsma, Delfabbro, Gradisar, and Griffiths (2013)

(Markey \& Ferguson, 2017)

\{Kardefelt-Winther, 2015 \#158\}

Starcevic (2017)

Ko and Yen (2014)

Kardefelt-Winther (2014)

King and Delfabbro (2014b)

Ko and Yen (2014)

Griffiths et al. (2016)

Király et al. (2017)

Griffiths et al. (2016)

Griffiths et al. (2016)

Griffiths et al. (2016)

Ko and Yen (2014)

Griffiths et al. (2016)

Kaptsis, King, Delfabbro, and Gradisar, (2016)

Kaptsis, King, Delfabbro, and Gradisar (2016)

Griffiths et al. (2016), Ko and Yen (2014)

(continued) 
Table 3. Continued

\begin{tabular}{|c|c|c|}
\hline \multirow[b]{2}{*}{ Topics } & \multicolumn{2}{|c|}{ Validity of the diagnostic criteria to identify individuals with GD. } \\
\hline & Concerns & Related references \\
\hline & $\begin{array}{l}\text { Problematic gamers appear to be driven by a need for } \\
\text { higher-quality, rarer, more valuable, more novel, or } \\
\text { more difficult-to-obtain rewards. }\end{array}$ & King and Delfabbro (2016) \\
\hline & $\begin{array}{l}\text { Individuals with IGD may have very different and } \\
\text { tolerance-unrelated reasons for spending more time } \\
\text { gaming. }\end{array}$ & $\begin{array}{l}\text { Billieux, Schimmenti, Khazaal, } \\
\text { Maurage, and Heeren (2015) }\end{array}$ \\
\hline & $\begin{array}{l}\text { The increase in time or upgradation of equipment does } \\
\text { not necessarily reflect a pathology. }\end{array}$ & Griffiths et al. (2016) \\
\hline & $\begin{array}{l}\text { This criterion excludes gamers that may have played a } \\
\text { considerable amount of time over a long period but } \\
\text { have not increased their playing time. }\end{array}$ & Krossbakken et al. (2017) \\
\hline Deception & $\begin{array}{l}\text { This criterion has a considerably lower diagnostic } \\
\text { accuracy compared with the other IGD criteria. }\end{array}$ & Ko et al. (2014) \\
\hline \multirow[t]{3}{*}{ Escape } & $\begin{array}{l}\text { This criterion has a considerably lower diagnostic } \\
\text { accuracy compared with the other IGD criteria. }\end{array}$ & $\begin{array}{l}\text { (Király et al., 2017; Király, } \\
\text { Griffiths, \& Demetrovics, 2015; } \\
\text { Ko \& Yen, 2014) \{Rehbein, } 2015 \\
\text { \#227\} }\end{array}$ \\
\hline & $\begin{array}{c}\text { Low specificity: Nonaddicted gamers also play to escape } \\
\text { problems in their lives. Gamers are not necessarily } \\
\text { aware that the purpose of their gaming is to escape } \\
\text { problems. }\end{array}$ & Griffiths et al. (2016) \\
\hline & $\begin{array}{l}\text { Numerous gamers view escaping and losing time as a } \\
\text { positive feature of gaming rather than a negative one. }\end{array}$ & Wood \& Griffiths (2007) \\
\hline Loss of interest & $\begin{array}{l}\text { Giving up other activities for gaming may reflect a } \\
\text { normal development process. It may also reflect an } \\
\text { association with depression. }\end{array}$ & Griffiths et al. (2016) \\
\hline \multirow[t]{2}{*}{$\begin{array}{l}\text { Risk or Lose relationships } \\
\text { and opportunities }\end{array}$} & $\begin{array}{l}\text { Highly engaged nondisordered players have also } \\
\text { endorsed this criterion. }\end{array}$ & Griffiths et al. (2016) \\
\hline & $\begin{array}{l}\text { Including functional impairment and distress to the } \\
\text { wording of each criterion would enable differentiation } \\
\text { between the engaged and addicted gamers using the } \\
\text { same scale. "Leading to clinically significant } \\
\text { impairment or distress" could be included in the } \\
\text { wording. }\end{array}$ & Krossbakken et al. (2017) \\
\hline General concern & $\begin{array}{l}\text { The field lacks basic theory, definitions, and properly } \\
\text { validated and standardized assessment tools. }\end{array}$ & $\begin{array}{l}\text { Van Rooij and Kardefelt- } \\
\text { Winther (2017) }\end{array}$ \\
\hline
\end{tabular}

and associated factors, such as impulsivity (Bailey et al., 2013; Ko et al., 2017; Rho et al., 2017; Ryu et al., 2018; Y. Wang et al., 2017), between GD and other substance use disorders. Brain imaging studies (e.g., Ko et al., 2013; Tian et al., 2014) and reveiws for gaming probems in child and adolescetns (Kuss \& Griffiths, 2012) also support these similarities, which may support the idea that GD and addictive disorders have a common manifestation or underlying mechanism (Young \& Brand, 2017).

Clinical and prospective studies are necessary to investigate the mechanisms of addiction (Subramaniam, 2014). However, the IGD and GD criteria in the DSM-5 and ICD11 respectively are indispensable for participant recruitment for these studies (Lee, Choo, \& Lee, 2017; Petry, Rehbein, Ko, \& O’Brien, 2015; Saunders et al., 2017).

\section{Moral panic}

Various levels of concern were expressed in articles regarding GD inclusion in diagnostic manuals causing overpathologizing of normal gaming behaviors (Aarseth et al., 2017; Billieux, Schimmenti, Khazaal, Maurage, \& Heeren, 2015; Van Rooij \& Kardefelt-Winther, 2017). Przybylski (2014) demonstrated a consistent, but not robust, association between gaming and children's adjustment. A small proportion of the general population $(0.3 \%-1.0 \%)$ fulfills the IGD criteria (Przybylski, Weinstein, \& Murayama, 2017). Furthermore, a clear link between IGD and psychological, social, or physical health problems has not been corroborated (Markey \& Ferguson, 2017). Therefore, Carbonell (2017) reported concerns regarding the existence of 
functional impairment in IGD. However, significant gaming-related problems, physical harm, emotional distress, and functional impairment in varied dimensions were revealed in several interview-based or epidemiological studies (King, Delfabbro, \& Griffiths, 2013; Ko et al., 2019; Lehenbauer-Baum et al., 2015; Müller et al., 2015; Rasmussen et al., 2015; Rikkers, Lawrence, Hafekost, \& Zubrick, 2016; Stubblefield et al., 2017; Subramaniam et al., 2016; Wong \& Lam, 2016). IGD prevalence ranges from 0.96 to $5.9 \%$ in survey studies on the basis of DSM-5 criteria (Bouna-Pyrrou, Mühle, Kornhuber, \& Lenz, 2015; Chiu, Pan, \& Lin, 2018; Demetrovics et al., 2012; Evren et al., 2018; Lemmens, Valkenburg, \& Gentile, 2015; Pontes, Király, Demetrovics, \& Griffiths, 2014; Rehbein, Kliem, Baier, Mößle, \& Petry, 2015a; Subramaniam et al., 2016; Vadlin, Åslund, Rehn, \& Nilsson, 2015; H.; Yu \& Cho, 2016). The meta-analysis reported an overall IGD prevalence of $3.1 \%$ or $4.6 \%$, depending on the measurement and population (Fam, 2018; Ferguson, Coulson, \& Barnett, 2011). Furthermore, the false-negative rate of self-reported questionnaire evaluation is relatively high (44\%) (Jeong et al., 2018). Individuals with GD may resist participating in voluntary surveys (Yao, Potenza, \& Zhang, 2017), which may cause the underestimation of GD prevalence.

Another concern is that the GD criteria could exacerbate the moral panic related to gaming (Quandt, 2017; van Rooij et al., 2018). Basing criteria on substance use disorders may cause inappropriate diagnoses of GD. Furthermore, the proposed threshold fails to differentiate between highly engaged gamers and problematic or disordered users (Deleuze et al., 2017; Dowling, 2014; Kardefelt-Winther, 2014; Starcevic, 2017), particularly in adults (Carbonell, 2017). However, compared with alcohol use disorders (2 of 9 criteria) or gambling disorders (4 of 9 criteria), the threshold for the diagnosis of IGD in the DSM-5 (5 of 9 criteria) is relatively high (APA, 2013). Furthermore, studies have suggested that the cut-off point accurately identifies adults or adolescents with IGD (Ko et al., 2014; Koo et al., 2017).

Both the DSM-5 and ICD-11 criteria for IGD and GD respectively defined dyscontrol of gaming using typical addictive symptoms and negative consequences. They did not conclude that all types of gaming were problematic (APA, 2013; WHO, 2019). Identifying a clear line between GD and healthy engagement in gaming is difficult without a clear definition, such as that provided in the DSM-5 or ICD11 (Ko, 2014). Furthermore, unwillingness to recognize the addictive potential of gaming may lead the affected individuals to a higher health risk (Lee et al., 2017), which should be addressed using effective treatments, such as cognitive behavior therapy, mindfulness, or family-based interventions (Kim \& Noh, 2019; Li et al., 2017; Zajac, Ginley, Chang, \& Petry, 2017). Billieux et al. (2017) reported that terms commonly used by the public without clear definitions (such as "addiction") may contribute more to a moral panic than a clear definition. Király and Demetrovics (2017) indicated that providing easily understandable public education regarding the definitions of IGD and GD (particularly the distress threshold) may help prevent moral panic and misinterpretation.

3. The validity of the criteria for distinguishing patients with GD from healthy gamers

Extensive concerns have been raised regarding the majority of the DSM-5 criteria for IGD, all of which are listed in Table 3. These concerns can be classified into four categories.

The first category is related to the nosology of the criteria. Because gaming does not induce pharmacological effects, the withdrawal symptoms vary in presentation, onset, and duration, and they are thus difficult to define (Ko, 2014). King, Haagsma, Delfabbro, Gradisar, \& Griffiths (2013) indicated that withdrawal is a major element of the definition of GD in screening instruments. Most gamers assessed by Ko et al. (2014) declared that they could not abstain from gaming for several days. A study demonstrated that $88 \%$ of individuals with GD experienced withdrawal symptoms within 3 days after stopping gaming (Ko et al., 2019). However, a prospective study determined that individuals with GD experienced the largest decline in withdrawal symptomatology within the first 24 hours of abstinence (Kaptsis, King, Delfabbro, \& Gradisar, 2016a). Furthermore, the emotional reaction to not playing games and the symptoms occurring because of withdrawal, such as irritability and restlessness, were often confused (Kaptsis, King, Delfabbro, \& Gradisar, 2016b).

The second category is related to the criteria not having the capacity to differentiate gamers with GD from highly engaged but healthy gamers (Kardefelt-Winther, 2015). Several criteria, such as preoccupation (Kardefelt-Winther, 2014), escape (Rehbein et al., 2015a), or loss of interest (Griffiths et al., 2016), reportedly manifest among both individuals with GD and healthy engaged gamers. Ko et al. (2014) further argued that the escape and deception criteria had relatively low diagnostic accuracy, as demonstrated by psychometric assessment studies (Király et al., 2017; Schivinski, Brzozowska-Woś, Buchanan, Griffiths, \& Pontes, 2018). However, escape is the most significant motivational predictor of GD with clinical utility (Billieux et al., 2011; Griffiths et al., 2016; Király et al., 2015; Kuss, Louws, \& Wiers, 2012; Martín-Fernández et al., 2016). Furthermore, loss of interest is critical for identifying individuals with GD, and it reflected the severity of GD in questionnaire studies (Lee et al., 2017; Rehbein et al., 2015a). Therefore, concerns and empirical study results for individual criteria were inconsistent.

Another key problem is the threshold of frequency and intensity level of each criterion, such as the number of times an individual loses control in 1 week and the consequences (Ko, 2014; Ko et al., 2019; Ko \& Yen, 2014). The DSM-5 set "leading to clinically significant impairment or distress" as the threshold for the overall diagnosis (APA, 2013). Kardefelt-Winther et al. (2017) suggested that distress should be repetition persisting over a significant period of time, and functionally impairing. Krossbakken, Pallesen, Molde, Mentzoni, and Finseras (2017) and van Rooij, 
Schoenmakers, and van de Mheen (2017) suggested that if functional impairment and distress were included in all the criteria, engaged and addictive gamers could be separated. Therefore, several scholars have suggested that problems resulting from gaming and functional impairment should be a required criterion to prevent GD overdiagnosis (Griffiths et al., 2016; King \& Delfabbro, 2018; Ko, 2014; van Rooij et al., 2017). Furthermore, a threshold may attenuate the false-positive rates of each criterion by establishing consensus regarding severity and frequency (Ko, 2014).

The third concern is related to the wording of the criteria. The most common concern is related to determining tolerance based on time (Billieux et al., 2015; Griffiths et al., 2016; Ko \& Yen, 2014; Krossbakken et al., 2017). Chronic cases spent a large amount of time gaming and could not further prolong gaming time (Ko, 2014). Several scholars have suggested that diminished levels of gaming satisfaction because of prolonged gaming activity can represent tolerance (Griffiths et al., 2016; King \& Delfabbro, 2016; Ko \& Yen, 2014). A study reported that tolerance was critical in identifying individuals with GD (Rehbein, Kliem, Baier, Mößle, \& Petry, 2015b), whereas another determined that it was not a valid criterion (Lee et al., 2017), depending on the interpretation of tolerance.

Kardefelt-Winther (2014) argued that preoccupation is not necessarily an indicator of pathology. King and Delfabbro suggested that cognitive factors related to preoccupation must be clarified (King \& Delfabbro, 2014b) and Griffiths et al. (2016) suggested assessing preoccupation based on their "perception of gaming as central to their lives" or "whether they could imagine their lives without gaming," whereas Ko and Yen (2014) evaluated preoccupation based on "distraction caused by thoughts of gaming when they must concentrate on work or other important tasks" to reflect a functional disturbance. Furthermore, Király et al. (2017) demonstrated the relatively low diagnostic accuracy of preoccupation in a survey study. Therefore, varied methods have been suggested to evaluate the concept of preoccupation, which may affect performance in diagnosing GD.

The fourth concern related the definition of excluding criteria, to prevent inappropriate recruitment of subjects with behaviors similar to GD caused by other psychological conditions. Ko et al. (2009) proposed excluding criteria to distinguish patients that are "better accounted for by psychotic disorder, bipolar I disorder, or other impulse control disorders." These criteria would prevent the diagnosis of GD because of over-engagement in gaming secondary to a delusion or under a manic state. The DSM- 5 criteria excluded gambling behaviors and viewing of sexual Internet content (APA, 2013) because these behaviors may be more accurately accounted for by gambling disorder or sexual motivation, respectively.

Kardefelt-Winther et al. (2017) suggested excluding criteria that are more accurately explained by an underlying disorder, a willful choice, or a coping strategy. These proposals remind clinicians to emphasize the reasons or factors underlying GD. However, Griffiths (2017) argued that few individuals would be diagnosed as addicts if these exclusion criteria, such as gaming as a coping strategy, were applied for substance use disorders (e.g., drinking as a coping strategy).

Carbonell (2017) raised concerns regarding the stability of diagnosis. A study demonstrated that self-identified excessive gaming tends to be relatively transient (Konkoly Thege, Woodin, Hodgins, \& Williams, 2015), which may explain why a duration of 12 months was required for both DSM-5 and ICD-11 criteria for IGD and GD respectively. However, studies revealed the stability of GD criteria over 6 months and 2 years (Bouna-Pyrrou et al., 2018; Weinstein, Przybylski, \& Murayama, 2017). These studies demonstrated in-conclusive results in the course of GD.

Despite these concerns, the proposed diagnostic threshold of 5 of 9 criteria, with the requirement of impaired function and distress, may effectively differentiate individuals with IGD from highly engaged but healthy gamers (Ko et al., 2014; Koo et al., 2017). The psychometric validity of the proposed threshold has been supported by various studies (Bouna-Pyrrou et al., 2018; Király et al., 2017; Sigerson, Li, Cheung, Luk, \& Cheng, 2017).

\section{Concerns regarding the ICD-11 GD criteria}

Several researchers have argued that diagnosis with the ICD11 guidelines may be premature because of inadequate scientific evidence (van Rooij et al., 2018). However, many of other clinicians and researchers support the WHO's decision, which was based on clinical evidence and public health requirements (Higuchi et al., 2017; Rumpf et al., 2018). More advantages than disadvantages have presented regarding GD inclusion in ICD-11 (Király \& Demetrovics, 2017; Shadloo et al., 2017; van den Brink, 2017). However, some concerns persist and scientific problems continue to be raised (Aarseth et al., 2017; van Rooij et al., 2018). The specific concerns are not listed in the present paper because most of the concerns raised regarding the ICD-11 GD definition are similar to those raised regarding the DSM-5 GD criteria.

The ICD developed the criteria for GD after gathering a considerable amount of evidence on DSM-5 criteria and made some critical changes. First, functional impairment and negative consequences were set as obligatory requirements (Billieux et al., 2017; Griffiths et al., 2016; Ko, 2014; Krossbakken et al., 2017). Criteria with controversial validity, such as escape or deceptive behaviors (Ko et al., 2014), or ill-defined criteria, such as tolerance and withdrawal (Billieux et al., 2015; Kaptsis et al., 2016b; Ko, 2014), were excluded. The three aforementioned basic criteria must be fulfilled for a positive GD diagnosis. Therefore, the ICD11 definition has a high diagnostic threshold that may attenuate overdiagnosis risk. However, no threshold can entirely prevent false-positive cases without causing excessive false-negative cases; this is another critical concern (Maraz, Király, \& Demetrovics, 2015).

Individuals with repeated intermittent negative consequences but without impaired function may not be diagnosed and treated as GD because functional impairment is 
required for the diagnosis (Colder Carras \& KardefeltWinther, 2018). The ICD-11 defined excessive gaming with a risk of mental or physical problems or risky behaviors as hazardous gaming, and the disorder was categorized under "problems associated with health behaviors" (WHO, 2019) which remind individuals to alter their behavior habits to improve their health. A study determined that $15.9 \%$ of highly engaged gamers fulfilled the definition of hazardous gaming presented by the ICD-11 (Ko et al., 2019). Therefore, the hazardous gaming definition could be used to identify individuals with GD risk at an earlier stage. Nevertheless, further evidence-based information regarding the harms of excessive gaming is required (King \& Delfabbro, 2018).

\section{DISCUSSION}

Numerous researchers have readied concerns regarding defining GD as an addictive disorder because of its psychiatric comorbidity and heterogeneity in etiology. However, substance use disorders are modeled by various frameworks, such as the self-medication model (Koffarnus \& Kaplan, 2018), decision-making model (Verdejo-Garcia, Chong, Stout, Yucel, \& London, 2018), and rewarding deficit model (Cooper, Robison, \& Mazei-Robison, 2017). Furthermore, empirical results support the similarities between GD and other addictive disorders. Moreover, retaining the comorbidity model to represent the coexisting psychiatric symptoms of GD could be a practical clinical approach, instead of negating the addiction framework. Nevertheless, these concerns should remind researchers and clinicians to consider multiple underlying factors that contribute to individual clinical manifestations of GD. Clinical, experimental, prospective, and neurobiological studies could provide etiological information, which is necessary to validate the addiction framework of GD.

Concerns were repeatedly expressed regarding GD criteria over-pathologizing healthy engaged gaming behaviors. The existence of functional impairment in GD was also doubted. Several scholars suggested that the diagnostic criteria could cause a moral panic regarding gaming behaviors (Aarseth et al., 2017; Kardefelt-Winther, 2014; Markey \& Ferguson, 2017; van Rooij et al., 2018). However, several studies have demonstrated that the DSM-5 or ICD11 criteria could distinguish IGD from engaged gamers and reveal functional impairments (Ko et al., 2014; Ko et al., 2019; Koo et al., 2017). Diagnostic criteria that provide a clear definition for disordered gaming could prevent overpathologizing healthy gaming behavior. Therefore, welldesigned public education is necessary to prevent the misunderstanding of criteria. Further clinical studies to demonstrate the negative consequences, functional impairment, and course of GD are required to abate concerns.

Concerns and inconclusive results have been reported for the nosology (e.g., "withdrawal"), diagnostic validity (e.g., "escape"), and wording (e.g., "tolerance") of individual criteria for GD diagnosis. However, several diagnostic interviewing studies support the overall discriminative validity of the DSM-5 criteria (Ko et al., 2014; Koo et al., 2017). The ICD-11 criteria for GD were improved with the inclusion of negative consequences and functional impairments as a required criterion and exclusion of inconclusive criteria. However, the clinical validity and utility warrant further investigation. The stability, threshold, neurobiological framework, discriminative performance, and predictivity of the GD criteria should be evaluated in clinical prospective studies to further improve their validity and utility.

\section{Suggestions to resolve the concerns regarding the DSM-5 IGD and ICD-11 GD criteria}

We suggest designing studies that include investigation of (i) the diagnostic validity of the GD criteria, (ii) the underlying etiological factors of GD, (iii) the negative consequences of GD, and (iv) the course and prognosis of GD. Furthermore, an integrated review or debate conference would be beneficial in resolving concerns. In the following sections, we discuss each of these suggestions in detail.

\section{Diagnostic validity of the GD criteria}

The most challenging aspect of validity studies on GD criteria is identifying the gold standard group and the optimal control group. Individuals with excessive gaming habits who demonstrate both typical addictive symptoms and chronic functional impairments could be eligible as members of the gold standard group. The clinical impression derived from diagnostic interviews performed by experienced mental health professionals based on the ICD11 definition could be the standard for the recruitment of the gold standard group. Furthermore, recruiting nongamers as control group members may overestimate the diagnostic validity of the criteria in a clinical situation. Therefore, including regular or highly engaged gamers who do not meet the GD criteria in the control group is reasonable.

Studies have supported the validity of the DSM-5 IGD criteria in diagnostic interviewing studies (Ko et al., 2014; Koo et al., 2017; Müller et al., 2019). However, these studies displayed differences in criteria validity. Even though the same criteria were used (the DSM-5 IGD criteria), the intensity thresholds differed because they were derived from the personal judgment of the interviewers. Therefore, researchers must carefully consider the intensity and frequency thresholds (Ko, 2014; Starcevic, 2017) of each criterion to provide a standard assessment for diagnosis.

Case-control studies, particularly with clinical samples, could be used to evaluate the optimal thresholds for the criteria and definitions (e.g., the number of criteria required for the diagnosis) (Ko et al., 2019). The performance of these thresholds should then be tested among regular gamers in large-scale epidemiological studies.

\section{Etiological mechanisms underlying GD}

One of the most apt definitions of addiction is "decreased reward sensitivity and increased expectation sensitivity 
conspire to overwhelm the brain's control circuit" (Volkow et al., 2010). In other words, addiction involves reward, expectation, and cognitive control circuits. Mechanism based on these circuits should be investigated in GD to assess the similarities and differences with substance use disorders. The cue-induced craving model (Weinstein, 2017) and the impaired cognitive control model (Kuss et al., 2018) of GD were the most consistent results in this area. However, these also yield inconsistent results concerning the brain regions responsible for craving reaction or cognitive control. Furthermore, the experimental design was limited. Therefore, well-designed neurocognitive experimental studies should be conducted, such as studies that use functional magnetic resonance imaging (fMRI), positron emission tomography, and electroencephalography (EEG) and enroll adequate sample sizes through diagnostic interviewing with a reasonable hypothesis (Ko, 2014). The combination of these results and information from behavioral tasks and psychological assessments would contribute to validating or rejecting the addiction framework of GD.

Furthermore, research with clinical samples of GD could investigate other candidate mechanisms, such as impulse control, stress vulnerability (Canale et al., 2019), emotion regulation, and decision-making (Ko et al., 2017). Comorbidity should be evaluated and specified in mechanism studies because of the high rate of psychiatric comorbidity among individuals with IGD (e.g., 39.1\% adults with IGD have ADHD [Yen et al., 2017]) to demonstrate their role in the development of IGD. Intervention studies focusing on each specific mechanism are required to demonstrate the role of these theoretical frameworks in the development, maintenance, remission, and relapse of GD.

\section{Studies focusing on the negative consequences of GD}

Both Van Rooij and Prause (2014) and Browne et al. (2016) have suggested examining how GD harms an individual. A diagnostic interview study demonstrated that $89.9 \%$ of IGD patients fulfilled at least one functional impairment criterion (Ko et al., 2019). However, functional impairments varied based on gaming design. Games were usually designed to demand an increasing amount of time, e.g., 2-3 h per section, from users, during which a user is unable to perform other tasks. Nowadays, smartphone games are designed to attract users to touch the screen repeatedly and frequently to entice users to play and thus distracts gamers from their duties and responsibilities, which may result in deficient work performance or accidents (e.g., while driving or cooking). Potenza (2018) reported that a hospitalized patient passed away because a care provider was gaming and was thus distracted from his work-related task.

The mental and physical negative consequences of GD may include sleep disturbances (Hawi, Samaha, \& Griffiths, 2018; Mannikko, Billieux, \& Kaariainen, 2015), obesity (Ko et al., 2019), and cardiovascular disorders (Braithwaite, Shirtcliffe, Jurevics, \& Beasley, 2018). Moreover, accidents that occur as a result of overindulging in smartphone gaming (e.g., car accidents both as a driver or a pedestrian) could present a new problem for individuals with GD or even highly engaged healthy gamers. Finally, "Loot Boxes" are randomized consumable virtual items that can be obtained by expending effort in the game or by paying real money. This system may cause severe financial problems (Zendle, Meyer, \& Over, 2019). Studies to demonstrate the association between these problems and GD and prospective studies to investigate the causal relationships are necessary to understand the negative consequences of GD.

Moreover, some gaming-related problems, such as sleep disturbances or immobilization (Ko et al., 2019), result from excessive or "binge" gaming (i.e., extremely long gaming sessions) and are thus not necessarily caused by GD, which should be considered by mental health professionals and esport teams, companies and sponsors, who should devise strategies to protect their gamers from physical and psychological problems. These strategies could involve limiting the duration of immobility or visual exposure to the screen, encouraging or even obliging exercise, and encouraging healthy sleep habits. Furthermore, the possible negative consequences associated with "binge gaming" should also be considered when designing games, particularly for children and adolescents (Király et al., 2018).

\section{Prospective studies examining GD course and prognosis}

The most essential standard for the DSM-5 IGD criteria is its clinical utility, in terms of the assessment of clinical course and treatment response (APA, 2013). Weinstein et al. (2017) reported moderate stability of the GD criteria in a half-year follow-up study. Longer follow-up periods for individuals of GD may provide more information on the course and prognosis of GD (Petry et al., 2015). Prospective studies that provide the time course could clarify the causal relationship between GD and associated mental and physical health problems (Mihara \& Higuchi, 2017; Petry et al., 2015). For example, social skills, emotional regulation deficits, attention problems, impulsivity, and self-esteem predict GD, whereas depression, anxiety, poor school performance, and emotional stress are outcomes of GD in prospective study (Ferguson \& Ceranoglu, 2014; Gentile et al., 2011; Wartberg, Kriston, Zieglmeier, Lincoln, \& Kammerl, 2019; Wichstrom, Stenseng, Belsky, von Soest, \& Hygen, 2019). These studies have provided key information supporting the causal relationship between GD and its associated factors. However, they were based on self-reported questionnaires. Diagnostic interview studies, which prospectively investigate the relapse, remission, or exacerbation of GD and the negative consequences could clarify the separation of the stages of the disorder (Király et al., 2015; Petry et al., 2015) and the clinical utility of the GD classification.

\section{Integrated reviews, theory proposals, and debate conferences}

A holistic theoretical framework based on integrated empirical findings were lacking despite a large body of 
findings on the psychological, social, and neurobiological factors of GD (Müller, 2017). The associations identified in cross-sectional studies could contribute to the meaningful hypotheses regarding the risk factors for GD and provide foundations for future confirmative research, as suggested by Kuss et al. (2017b). However, without an integrated review, the massive body of information cannot be utilized efficiently. Kuss, Pontes, and Griffiths (2018) reviewed the neurobiological correlations of GD, such as poor cognitive control and emotion regulation. Dong and Potenza (2014) proposed a cognitive behavior model of IGD, which highlighted the domains of reward-seeking, stress-reduction driving motivations, executive control, and decision-making. A systemic review claimed that deficient self-esteem, mood and reward dysregulation, problems in decision-making, and external factors could be etiological factors for GD (Paulus, Ohmann, von Gontard, \& Popow, 2018). Sugaya, Shirasaka, Takahashi, and Kanda (2019) raised concerns regarding sleep disturbances, family factors, and impaired cognitive control of GD. These reviews integrated previous studies and provided an outline of the scope for etiological and prospective studies.

A unified methodology for assessment and a practical intervention should be developed as soon as possible. One practical means is to integrate available evidence-based information and clinical experience from experts in different countries over the world. Griffiths et al. (2016) argued that debate could lead to an improved theory, better methodologically designed studies, and more robust empirical evidence regarding problematic gaming and its psychosocial effects and consequences. A practical approach to advance a constructive debate in this field is the release of special issues in journals of interest where opinions can be compared and engaged with. Furthermore, international conferences, such as the International Conference on Behavioral Addictions (ICBA), could provide a platform to discuss unresolved concerns to achieve a consensus regarding resolutions. At the sixth ICBA in 2019 , the WHO established a working group to lead The WHO Collaborative Project on the Development of International Screening Tools for Disorders caused by Addictive Behaviors (Carragher et al., 2019). The project aimed to develop (i) a lay-administered fully structured diagnostic interview for GD, (ii) a clinician-administered semi-structured diagnostic interview for GD, and (iii) diagnostic research criteria for GD. The working group comprises experts from across the world to integrate their knowledge and thus establish assessment tools that can be applied globally. By integrating information, experience, and the opinions of mental health professionals and scholars, we might move forward to develop a practical means to assess individuals with GD to help them and their families.

\section{Limitations}

The present study was conducted using the PubMed database alone, which may have limited the extent of articles included. Furthermore, some recommendations in the recruited articles were based on the opinions of individual authors. Therefore, these findings must be verified in future studies.

\section{CONCLUSION}

The results of empirical studies have supported the similarities between GD and addictive disorders, despite concerns regarding the heterogeneity among GD etiologies. Neurobiological mechanisms of addiction should be evaluated using experimental studies in patients with GD. A clear definition of GD could identify individuals who require assistance without pathologizing healthy gamers. Public education is required to prevent misinterpretation of GD criteria and moral panic. Extensive concerns and inconclusive results regarding the validity or utility of individual DSM-5 IGD criteria have been reported. However, the current requirements for diagnosis are presenting five of nine criteria with functional impairment, which should differentiate individuals with GD from highly engaged but healthy gamers. Further empirical research on functional impairment, course and prognosis, and stability and predictivity of criteria are required to verify the validity and utility of the IGD and GD criteria. Considering these concerns is critical in preventing overdiagnosis, underdiagnosis, misdiagnosis, or harm to patients. In this review, we suggested assessing the addiction characteristics, negative consequences, and psychiatric comorbidities of video gaming before making a final diagnosis. Identifying and working to resolve concerns regarding the diagnostic criteria through scientific studies is the first step toward the successful treatment of GD.

Conflict of interest: ZD has been member of a WHO advisory group on the public health consequences of addictive behaviors. In this capacity he has been eligible for travel support from WHO or the host center to attend advisory group meetings but have not been remunerated for their work. ZD is the Editor-in-Chief of the Journal of Behavioral Addictions.

Acknowledgments: This study was supported by the Taiwan Ministry of Science and Technology (MOST105-2314-B037-027-MY2, MOST107-2314-B-037-101-MY2), Kaohsiung Municipal Hsiao-Kang Hospital (KMHK-104-006; KMHK-103-008), Kaohsiung Medical University Hospital (KMUH105-5R54; KMUH106-6R71), and the Research Center for Environmental Medicine of the Kaohsiung Medical University in Taiwan from the Featured Areas Research Center Program within the framework of the Higher Education Sprout Project by the Ministry of Education in Taiwan. Orsolya Király was supported by the János Bolyai Research Scholarship of the Hungarian Academy of Sciences and by the ÚNKP-19-4 New National Excellence Program of the Ministry for Innovation and Technology. Zsolt Demetrovics was supported by the 
Hungarian National Research, Development and Innovation Office (KKP126835). These institutions had no role in the design, process, analysis, and production of the present study.

\section{REFERENCES}

* - Papers found during the literature search

\# - Papers found in the reference lists of the papers found during the literature search

*Aarseth, E., Bean, A. M., Boonen, H., Colder Carras, M., Coulson M., Das, D., et al. (2017). Scholars' open debate paper on the world health organization ICD-11 gaming disorder proposal. Journal of Behavioral Addictions, 6(3), 267-270. https://doi.org/ 10.1556/2006.5.2016.088.

American Psychiatric Association. (2013). Diagnostic and statistical manual of mental disorders (DSM-5). Washington, DC: American Psychiatric Association.

${ }^{\star}$ Bailey, K., West, R., \& Kuffel, J. (2013). What would my avatar do? Gaming, pathology, and risky decision making. Frontiers in Psychology, 4. https://doi.org/10.3389/fpsyg.2013.00609.

Billieux, J., Chanal, J., Khazaal, Y., Rochat, L., Gay, P., Zullino, D., et al. (2011). Psychological predictors of problematic involvement in massively multiplayer online role-playing games: Illustration in a sample of male cybercafe players. Psychopathology, 44(3), 165-171. https://doi.org/10.1159/000322525.

\#Billieux, J., King, D. L., Higuchi, S., Achab, S., Bowden-Jones, H., Hao, W., et al. (2017). Functional impairment matters in the screening and diagnosis of gaming disorder. Journal of Behavioral Addictions, 6(3), 285-289. https://doi.org/10.1556/2006.6.2017. 036.

\#Billieux, J., Schimmenti, A., Khazaal, Y., Maurage, P., \& Heeren, A. (2015). Are we overpathologizing everyday life? A tenable blueprint for behavioral addiction research. Journal of Behavioral Addictions, 4(3):119-123. https://doi.org/10.1556/2006.4. 2015.009.

*Bouna-Pyrrou, P., Aufleger, B., Braun, S., Gattnar, M., Kallmayer, S., Wagner, H., et al. (2018). Cross-sectional and longitudinal evaluation of the social network use disorder and internet gaming disorder criteria. Frontiers in Psychiatry, 9, 692. https:// doi.org/10.3389/fpsyt.2018.00692.

*Bouna-Pyrrou, P., Mühle, C., Kornhuber, J., \& Lenz, B. (2015). Internet gaming disorder, social network disorder and laterality: Handedness relates to pathological use of social networks. $J$ Neural Transm (Vienna), 122(8), 1187-1196. https://doi.org/10. 1007/s00702-014-1361-5.

Braithwaite, I., Shirtcliffe, P., Jurevics, R., \& Beasley, R. (2018). Gaming: A 21st century variant of seated immobility thromboembolism. New Zealand Medical Journal, 131(1469), 66-68.

*van den Brink, W. (2017). ICD-11 gaming disorder: Needed and just in time or dangerous and much too early? Journal of Behavioral Addictions, 6(3), 290-292. https://doi.org/10.1556/ 2006.6.2017.040.

\#Browne, M., Langham, E., Rawat, V., Greer, N., Li, E., Rose, J., et al. (2016). Assessing gambling-related harm in Victoria: A public health perspective. Melbourne, Australia: Victorian Responsible Gambling Foundation.
Cade, R., \& Gates, J. (2017). Gamers and video game culture: An introduction for counselors. The Family Journal, 25(1), 70-75. https://doi.org/10.1177/1066480716679809.

Canale, N., Marino, C., Griffiths, M. D., Scacchi, L., Monaci, M. G., \& Vieno, A. (2019). The association between problematic online gaming and perceived stress: The moderating effect of psychological resilience. Journal of Behavioral Addictions, 8(1), 174-180. https://doi.org/10.1556/2006.8.2019.01.

${ }^{\star}$ Carbonell, X. (2017). From Pong to Pokemon Go, catching the essence of the internet gaming disorder diagnosis. Journal of Behavioral Addictions, 6(2), 124-127. https://doi.org/10.1556/ 2006.6.2017.010.

Carragher, N., Rumpf, H. J., Higuchi, S., Billieux, J., King, D., Bowden-Jones, H., et al. (2019). World health organization (WHO) collaborative project on the development of an international diagnostic interview for gaming disorder. Journal of Behavioral Addictions, 8(Suppl. 1), 59.

${ }^{\star}$ Chiu, Y. C., Pan, Y. C., \& Lin, Y. H. (2018). Chinese adaptation of the Ten-Item Internet Gaming Disorder Test and prevalence estimate of Internet gaming disorder among adolescents in Taiwan. Journal of Behavioral Addictions, 7(3), 719-726. https://doi.org/10.1556/2006.7.2018.92.

${ }^{*}$ Colder Carras, M., \& Kardefelt-Winther, D. (2018). When addiction symptoms and life problems diverge: A latent class analysis of problematic gaming in a representative multinational sample of European adolescents. European Child \& Adolescent Psychiatry, 27(4), 513-525. https://doi.org/10.1007/ s00787-018-1108-1.

Cooper, S., Robison, A. J., \& Mazei-Robison, M. S. (2017). Reward circuitry in addiction. Neurotherapeutics, 14(3), 687-697. https://doi.org/10.1007/s13311-017-0525-z.

${ }^{*}$ Deleuze, J., Nuyens, F., Rochat, L., Rothen, S., Maurage, P., \& Billieux, J. (2017). Established risk factors for addiction fail to discriminate between healthy gamers and gamers endorsing DSM-5 Internet gaming disorder. Journal of Behavioral Addictions, 6(4), 516-524. https://doi.org/10.1556/2006.6.2017. 074.

Demetrovics, Z., Urbán, R., Nagygyörgy, K., Farkas, J., Griffiths, M. D., Pápay, O., et al. (2012). The development of the problematic online gaming questionnaire (POGQ). PLoS One, 7(5), e36417. https://doi.org/10.1371/journal.pone.0036417.

${ }^{\star}$ Dong, G., Liu, X., Zheng, H., Du, X., \& Potenza, M. N. (2019). Brain response features during forced break could predict subsequent recovery in internet gaming disorder: A longitudinal study. Journal of Psychiatric Research, 113, 17-26. https:// doi.org/10.1016/j.jpsychires.2019.03.003.

\#Dong, G., \& Potenza, M. N. (2014). A cognitive-behavioral model of Internet gaming disorder: Theoretical underpinnings and clinical implications. Journal of Psychiatric Research, 58, 7-11. https://doi.org/10.1016/j.jpsychires.2014.07.005.

${ }^{\star}$ Dowling, N. A. (2014). Issues raised by the DSM-5 internet gaming disorder classification and proposed diagnostic criteria. Addiction, 109(9), 1408-1409. https://doi.org/10.1111/add. 12554.

${ }^{\star}$ Duven, E. C., Müller, K. W., Beutel, M. E., \& Wölfling, K. (2015). Altered reward processing in pathological computer gamersERP-results from a semi-natural gaming-design. Brain Behav, 5(1), 13-23. https://doi.org/10.1002/brb3.293. 
${ }^{\star}$ Evren, C., Dalbudak, E., Topcu, M., Kutlu, N., Evren, B., \& Pontes, H. M. (2018). Psychometric validation of the Turkish nine-item internet gaming disorder scale-short form (IGDS9-SF). Psychiatry Research, 265, 349-354. https://doi.org/10.1016/j. psychres.2018.05.002.

${ }^{\star}$ Fam, J. Y. (2018). Prevalence of internet gaming disorder in adolescents: A meta-analysis across three decades. Scandinavian Journal of Psychology, 59(5), 524-531. https://doi.org/10.1111/ sjop.12459.

${ }^{\star}$ Ferguson, C. J., \& Ceranoglu, T. A. (2014). Attention problems and pathological gaming: Resolving the 'chicken and egg' in a prospective analysis. The Psychiatric Quarterly, 85(1), 103-110. https://doi.org/10.1007/s11126-013-9276-0.

${ }^{\star}$ Ferguson, C. J., Coulson, M., \& Barnett, J. (2011). A meta-analysis of pathological gaming prevalence and comorbidity with mental health, academic and social problems. Journal of Psychiatric Research, 45(12), 1573-1578. https://doi.org/10.1016/j. jpsychires.2011.09.005.

Gentile, D. A., Choo, H., Liau, A., Sim, T., Li, D., Fung, D., et al. (2011). Pathological video game use among youths: A two-year longitudinal study. Pediatrics, 127(2), e319-e329. https://doi. org/10.1542/peds.2010-1353.

González-Bueso, V., Santamaría, J. J., Fernández, D., Merino, L., Montero, E., \& Ribas, J. (2018). Association between internet gaming disorder or pathological video-game use and comorbid psychopathology: A comprehensive review. International Journal of Environmental Research and Public Health, 15(4). https://doi.org/10.3390/ijerph15040668.

Granic, I., Lobel, A., \& Engels, R. C. M. E. (2014). The benefits of playing video games. The American Psychologist, 69(1), 66-78. https://doi.org/10.1037/a0034857.

\#Griffiths, M. D. (2017). Behavioural addiction and substance addiction should be defined by their similarities not their dissimilarities. Addiction, 112(10), 1718-1720. https://doi.org/10. 1111/add.13828.

Griffiths, M. D., King, D. L., \& Demetrovics, Z. (2014). DSM-5 internet gaming disorder needs a unified approach to assessment. Neuropsychiatry, 4(1), 1-4. https://doi.org/10.2217/npy. 13.82.

${ }^{\star}$ Griffiths M. D., van Rooij, A. J., Kardefelt-Winther, D., Starcevic, V., Király, O., Pallesen, S., et al. (2016) Working towards an international consensus on criteria for assessing internet gaming disorder: A critical commentary on Petry et al. Addiction, 111(1), 167-175. https://doi.org/10.1111/add.13057.

Hawi, N. S., Samaha, M., \& Griffiths, M. D. (2018). Internet gaming disorder in Lebanon: Relationships with age, sleep habits, and academic achievement. Journal of Behavioral Addictions, 7(1), 70-78. https://doi.org/10.1556/2006.7.2018.16.

${ }^{\star}$ Higuchi, S., Nakayama, H., Mihara, S., Maezono, M., Kitayuguchi, T., \& Hashimoto, T. (2017). Inclusion of gaming disorder criteria in ICD-11: A clinical perspective in favor. Journal of Behavioral Addictions, 6(3), 293-295. https://doi.org/10.1556/ 2006.6.2017.049.

*van Holst, R. J., Lemmens, J. S., Valkenburg, P. M., Peter, J., Veltman, D. J., \& Goudriaan, A. E. (2012). Attentional bias and disinhibition toward gaming cues are related to problem gaming in male adolescents. Journal of Adolescent Health, 50(6), 541546. https://doi.org/10.1016/j.jadohealth.2011.07.006.
*Jeong, H., Yim, H. W., Lee, S. Y., Lee, H. K., Potenza, M. N., Kwon, J. H., et al. (2018). Discordance between self-report and clinical diagnosis of Internet gaming disorder in adolescents. Scientific Reports, 8(1), 10084. https://doi.org/10.1038/s41598-018-28478-8.

${ }^{\star}$ Kaess, M., Parzer, P., Mehl, L., Weil, L., Strittmatter, E., Resch, F., et al. (2017). Stress vulnerability in male youth with internet gaming disorder. Psychoneuroendocrinology, 77, 244-251. https://doi.org/10.1016/j.psyneuen.2017.01.008.

*Kaptsis, D., King, D. L., Delfabbro, P. H., \& Gradisar, M. (2016a). Trajectories of abstinence-induced internet gaming withdrawal symptoms: A prospective pilot study. Addictive Behaviors Reports, 4, 24-30. https://doi.org/10.1016/j.abrep.2016.06.002.

\#Kaptsis, D., King, D. L., Delfabbro, P. H., \& Gradisar, M. (2016b). Withdrawal symptoms in internet gaming disorder: A systematic review. Clinical Psychology Review, 43, 58-66. https:// doi.org/10.1016/j.cpr.2015.11.006.

${ }^{*}$ Kardefelt-Winther, D. (2014). Meeting the unique challenges of assessing internet gaming disorder. Addiction, 109(9), 15681570. https://doi.org/10.1111/add.12645.

${ }^{*}$ Kardefelt-Winther, D. (2015). Assessing the diagnostic contribution of internet gaming disorder criteria requires improved content, construct and face validity-a response to Rehbein and colleagues (2015). Addiction, 110(8), 1359-1360. https://doi. org/10.1111/add.12987.

\#Kardefelt-Winther, D., Heeren, A., Schimmenti, A., van Rooij, A., Maurage, P., Carras, M., et al. (2017). How can we conceptualize behavioural addiction without pathologizing common behaviours? Addiction, 112(10), 1709-1715. https://doi.org/ https://doi.org/10.1111/add.13763.

${ }^{*}$ Kim, S., \& Noh, D. (2019). The current status of psychological intervention research for internet addiction and internet gaming disorder. Issues in Mental Health Nursing, 40(4), 335341. https://doi.org/10.1080/01612840.2018.1534910.

\#King, D. L., \& Delfabbro, P. H. (2014a). The cognitive psychology of Internet gaming disorder. Clinical Psychology Review, 34(4), 298-308. https://doi.org/10.1016/j.cpr.2014.03.006.

\#King, D. L., \& Delfabbro, P. H. (2014b). Is preoccupation an oversimplification? A call to examine cognitive factors underlying internet gaming disorder. Addiction, 109(9), 1566-1567. https://doi.org/10.1111/add.12547.

\#King, D. L., \& Delfabbro, P. H. (2016). Defining tolerance in Internet Gaming disorder: Isn't it time? Addiction, 111(11), 2064-2065. https://doi.org/10.1111/add.13448.

${ }^{\star}$ King, D. L., \& Delfabbro, P. H. (2018). The concept of "harm" in Internet gaming disorder. Journal of Behavioral Addictions, 7(3), 562-564. https://doi.org/10.1556/2006.7.2018.24.

${ }^{\star}$ King, D. L., Delfabbro, P. H., \& Griffiths, M. D. (2013). Trajectories of problem video gaming among adult regular gamers: An 18-month longitudinal study. Cyberpsychology, Behavior, and Social Networking, 16(1), 72-76. https://doi.org/10.1089/ cyber.2012.0062.

\#King, D. L., Delfabbro, P. H., Potenza, M. N., Demetrovics, Z., Billieux, J., \& Brand, M. (2018). Internet gaming disorder should qualify as a mental disorder. Australian and New Zealand Journal of Psychiatry, 52(7), 615-617. https://doi.org/10. 1177/0004867418771189.

King, D. L., Delfabbro, P. H., Potenza, M. N., Demetrovics, Z., Billieux, J., \& Brand, M. (2019). Logic, evidence, and consensus: 
Towards a more constructive debate on gaming disorder. Australian and New Zealand Journal of Psychiatry, 53(11), 1047-1049. https://doi.org/10.1177/0004867419864435.

${ }^{\star}$ King, D. L., Haagsma, M. C., Delfabbro, P. H., Gradisar, M., \& Griffiths, M. D. (2013). Toward a consensus definition of pathological video-gaming: A systematic review of psychometric assessment tools. Clinical Psychology Review, 33(3), 331342. https://doi.org/10.1016/j.cpr.2013.01.002.

*Király, O., \& Demetrovics, Z. (2017). Inclusion of Gaming Disorder in ICD has more advantages than disadvantages. Journal of Behavioral Addictions, 6(3), 280-284. https://doi.org/10. 1556/2006.6.2017.046.

Király, O., Griffiths, M. D., \& Demetrovics, Z. (2015). Internet gaming disorder and the DSM-5: Conceptualization, debates, and controversies. Current Addiction Reports, 2(3), 254-262. https://doi.org/10.1007/s40429-015-0066-7.

Király, O., Griffiths, M. D., King, D. L., Lee, H. K., Lee, S. Y., Banyai, F., et al. (2018). Policy responses to problematic video game use: A systematic review of current measures and future possibilities. Journal of Behavioral Addictions, 7(3), 503-517. https://doi.org/10.1556/2006.6.2017.050.

${ }^{\star}$ Király, O., Sleczka, P., Pontes, H. M., Urbán, R., Griffiths, M. D., \& Demetrovics, Z. (2017). Validation of the ten-item internet gaming disorder test (IGDT-10) and evaluation of the nine DSM-5 internet gaming disorder criteria. Addictive Behaviors, 64, 253-260. https://doi.org/10.1016/j.addbeh.2015.11.005.

Király, O., Urban, R., Griffiths, M. D., Agoston, C., Nagygyorgy, K., Kokonyei, G., et al. (2015). The mediating effect of gaming motivation between psychiatric symptoms and problematic online gaming: An online survey. Medical Internet Research, 17(4), e88. https://doi.org/10.2196/jmir.3515.

\#Ko, C. H. (2014). Internet gaming disorder. Current Addiction Reports, 1(3), 177-185. https://doi.org/10.1007/s40429-0140030-y.

Ko, C. H., Lin, H. C., Lin, P. C., \& Yen, J. Y. (2019). Validity, functional impairment and complications related to Internet gaming disorder in the DSM-5 and gaming disorder in the ICD-11. Australian and New Zealand Journal of Psychiatry, 4867419881499. https://doi.org/10.1177/0004867419881499.

Ko, C. H., Liu, G. C., Yen, J. Y., Yen, C. F., Chen, C. S., \& Lin, W. C. (2013). The brain activations for both cue-induced gaming urge and smoking craving among subjects comorbid with Internet gaming addiction and nicotine dependence. Journal of Psychiatric Research, 47(4), 486-493. https://doi.org/10.1016/j. jpsychires.2012.11.008.

${ }^{\star}$ Ko, C. H., Wang, P. W., Liu, T. L., Chen, C. S., Yen, C. F., \& Yen, J. Y. (2017). The adaptive decision-making, risky decision, and decision-making style of Internet gaming disorder. Journal of the Association of European Psychiatrists, 44, 189-197. https:// doi.org/10.1016/j.eurpsy.2017.05.020.

${ }^{\star}$ Ko, C. H., \& Yen, J. Y. (2014). The criteria to diagnose internet gaming disorder from causal online gamer. Addiction, 109(9), 1411-1412. https://doi.org/10.1111/add.12565.

${ }^{\star}$ Ko, C. H., Yen, J. Y., Chen, S. H., Wang, P. W., Chen, C. S., \& Yen, C. F. (2014). Evaluation of the diagnostic criteria of Internet gaming disorder in the DSM-5 among young adults in Taiwan. Journal of Psychiatric Research, 53, 103-110. https://doi.org/10. 1016/j.jpsychires.2014.02.008.
Ko, C. H., Yen, J. Y., Chen, S. H., Yang, M. J., Lin, H. C., \& Yen, C. F. (2009). Proposed diagnostic criteria and the screening and diagnosing tool of Internet addiction in college students. Comprehensive Psychiatry, 50(4), 378-384. https://doi.org/10. 1016/j.comppsych.2007.05.019.

Koffarnus, M. N., \& Kaplan, B. A. (2018). Clinical models of decision making in addiction. Pharmacology, Biochemistry, and Behavior, 164, 71-83. https://doi.org/10.1016/j.pbb.2017.08.010.

\#Konkolÿ Thege, B., Woodin, E. M., Hodgins, D. C., \& Williams, R. J. (2015). Natural course of behavioral addictions: A 5-year longitudinal study. BMC Psychiatry, 15, 4. https://doi.org/10. 1186/s12888-015-0383-3.

${ }^{\star}$ Koo, H. J., Han, D. H., Park, S. Y., \& Kwon, J. H. (2017). The structured clinical interview for DSM-5 internet gaming disorder: Development and validation for diagnosing IGD in adolescents. Psychiatry Investigation, 14(1), 21-29. https://doi.org/ 10.4306/pi.2017.14.1.21.

*Krossbakken, E., Pallesen, S., Molde, H., Mentzoni, R. A., \& Finseras, T. R. (2017). Not good enough? Further comments to the wording, meaning, and the conceptualization of internet gaming disorder. Journal of Behavioral Addictions, 6(2), 114117. https://doi.org/10.1556/2006.6.2017.013.

*Kuss, D. J., \& Griffiths, M. D. (2012). Online gaming addiction in children and adolescents: A review of empirical research. Journal of Behavioral Addictions, 1(1), 3-22. https://doi.org/10. 1556/jba.1.2012.1.1.

${ }^{\star}$ Kuss, D. J., Griffiths, M. D., \& Pontes, H. M. (2017a). Chaos and confusion in DSM-5 diagnosis of Internet Gaming Disorder: Issues, concerns, and recommendations for clarity in the field. Journal of Behavioral Adictions, 6(2), 103-109. https://doi.org/ 10.1556/2006.5.2016.062.

${ }^{\star}$ Kuss, D. J., Griffiths, M. D., \& Pontes, H. M. (2017b). DSM-5 diagnosis of Internet Gaming Disorder: Some ways forward in overcoming issues and concerns in the gaming studies field. Journal of Behavioral Addictions, 6(2), 133-141. https://doi.org/ 10.1556/2006.6.2017.032.

${ }^{\star}$ Kuss, D. J., Louws, J., \& Wiers, R. W. (2012). Online gaming addiction? Motives predict addictive play behavior in massively multiplayer online role-playing games. Cyberpsychology, Behavior, and Social Networking, 15(9), 480-485. https://doi. org/10.1089/cyber.2012.0034.

${ }^{\star}$ Kuss, D. J., Pontes, H. M., \& Griffiths, M. D. (2018). Neurobiological correlates in internet gaming disorder: A systematic literature review. Frontiers in Psychiatry, 9, 166. https://doi.org/ 10.3389/fpsyt.2018.00166.

${ }^{\star}$ Lee, S. Y., Choo, H., \& Lee, H. K. (2017a). Balancing between prejudice and fact for Gaming Disorder: Does the existence of alcohol use disorder stigmatize healthy drinkers or impede scientific research? Journal of Behavioral Addictions, 6(3), 302305. https://doi.org/10.1556/2006.6.2017.047.

${ }^{\star}$ Lee, S. Y., Lee, H. K., Jeong, H., Yim, H. W., Bhang, S. Y., Jo, S. J., et al. (2017). The hierarchical implications of internet gaming disorder criteria: Which indicate more severe pathology? Psychiatry Investig, 14(3), 249-259. https://doi.org/10.4306/pi. 2017.14.3.249.

${ }^{\star}$ Lehenbauer-Baum, M., Klaps, A., Kovacovsky, Z., Witzmann, K., Zahlbruckner, R., \& Stetina, B. U. (2015). Addiction and engagement: An explorative study toward classification criteria 
for internet gaming disorder. Cyberpsychology, Behavior, and Social Networking, 18(6), 343-349. https://doi.org/10.1089/ cyber.2015.0063.

${ }^{\star}$ Lemmens, J. S., Valkenburg, P. M., \& Gentile, D. A. (2015). The internet gaming disorder scale. Psychological Assessment, 27(2), 567-582. https://doi.org/10.1037/pas0000062.

${ }^{\star}$ Li, W., Garland, E. L., McGovern, P., O’Brien, J. E., Tronnier, C., \& Howard, M. O. (2017). Mindfulness-oriented recovery enhancement for internet gaming disorder in U.S. Adults: A stage I randomized controlled trial. Psychology of Addictive Behaviors, 31(4), 393-402. https://doi.org/10.1037/adb0000269.

Liu, L., Yao, Y. W., Li, C. R., Zhang, J. T., Xia, C. C., Lan, J., et al. (2018). The comorbidity between internet gaming disorder and depression: Interrelationship and neural mechanisms. Frontiers in Psychiatry, 9, 154. https://doi.org/10.3389/fpsyt.2018.00154.

Mannikko, N., Billieux, J., \& Kaariainen, M. (2015). Problematic digital gaming behavior and its relation to the psychological, social and physical health of Finnish adolescents and young adults. Journal of Behavioral Addictions, 4(4), 281-288. https:// doi.org/10.1556/2006.4.2015.040.

\#Maraz, A., Király, O., \& Demetrovics, Z. (2015). Commentary on: Are we overpathologizing everyday life? A tenable blueprint for behavioral addiction research. The diagnostic pitfalls of surveys: If you score positive on a test of addiction, you still have a good chance not to be addicted. Journal of Behavioral Addictions, 4(3), 151-154. https://doi.org/10.1556/2006.4.2015.026.

\#Markey, P. M., \& Ferguson, C. J. (2017). Internet gaming addiction: Disorder or moral panic? American Journal of Psychiatry, 174(3), 195-196. https://doi.org/10.1176/appi.ajp.2016.16121341.

*Martín-Fernández, M., Matalí, J. L., García-Sánchez, S., Pardo, M., Lleras, M., \& Castellano-Tejedor, C. (2016). Adolescents with internet gaming disorder (IGD): Profiles and treatment response. Adicciones, 29(2), 125-133. https://doi.org/10.20882/ adicciones.890.

${ }^{\star}$ Mihara, S., \& Higuchi, S. (2017). Cross-sectional and longitudinal epidemiological studies of internet gaming disorder: A systematic review of the literature. Psychiatry and Clinical Neurosciences, 71(7), 425-444. https://doi.org/10.1111/pcn.12532.

\#Muller, K. W. (2017). Under the umbrella: Commentary on: Chaos and confusion in DSM-5 diagnosis of Internet Gaming Disorder: Issues, concerns, and recommendations for clarity in the field (Kuss et al.). Journal of Behavioral Addictions, 6(3), 313-316. https://doi.org/10.1556/2006.6.2017.011.

${ }^{\star}$ Muller, K. W., Beutel, M. E., Dreier, M., \& Wolfling, K. (2019). A clinical evaluation of the DSM-5 criteria for Internet Gaming Disorder and a pilot study on their applicability to further Internet-related disorders. Journal of Behavioral Addictions, 8(1) 16-24. https://doi.org/10.1556/2006.7.2018.140.

${ }^{\star}$ Muller, K. W., Janikian, M., Dreier, M., Wolfling, K., Beutel, M. E., Tzavara, C., et al. (2015). Regular gaming behavior and internet gaming disorder in European adolescents: Results from a crossnational representative survey of prevalence, predictors, and psychopathological correlates. European Child and Adolescent Psychiatry, 24(5), 565-574. https://doi.org/10.1007/s00787-014-0611-2.

\#Paulus, F. W., Ohmann, S., von Gontard, A., \& Popow, C. (2018). Internet gaming disorder in children and adolescents: A systematic review. Developmental Medicine and Child Neurology, 60(7), 645-659. https://doi.org/10.1111/dmcn.13754.
${ }^{\star}$ Pearcy, B. T., McEvoy, P. M., \& Roberts, L. D. (2017). Internet gaming disorder explains unique variance in psychological distress and disability after controlling for comorbid depression, OCD, ADHD, and anxiety. Cyberpsychology, Behavior, and Social Networking, 20(2), 126-132. https://doi.org/10.1089/ cyber.2016.0304.

${ }^{\star}$ Petry, N. M., Rehbein, F., Gentile, D. A., Lemmens, J. S., Rumpf, H. J., Mossle, T., et al. (2014a). An international consensus for assessing internet gaming disorder using the new DSM-5 approach. Addiction, 109(9), 1399-1406. https://doi.org/10. 1111/add.12457.

Petry, N. M., Rehbein, F., Gentile, D. A., Lemmens, J. S., Rumpf, H. J., Mossle, T., et al. (2014b). Moving internet gaming disorder forward: A reply. Addiction, 109(9), 1412-1413. https://doi.org/ 10.1111/add.12653.

${ }^{\star}$ Petry, N. M., Rehbein, F., Ko, C. H., \& O’Brien, C. P. (2015). Internet gaming disorder in the DSM-5. Current Psychiatry Reports, 17(9), 72. https://doi.org/10.1007/s11920-0150610-0.

*Pontes, H. M., Király, O., Demetrovics, Z., \& Griffiths, M. D. (2014). The conceptualisation and measurement of DSM-5 internet gaming disorder: The development of the IGD-20 test. PLoS One, 9(10), e110137. https://doi.org/10.1371/journal.pone. 0110137.

*Potenza, M. N. (2018). Do gaming disorder and hazardous gaming belong in the ICD-11? Considerations regarding the death of a hospitalized patient that was reported to have occurred while a care provider was gaming. Journal of Behavioral Addictions, 7(2), 206-207. https://doi.org/10.1556/2006.7.2018.42.

${ }^{*}$ Przybylski, A. K. (2014). Electronic gaming and psychosocial adjustment. Pediatrics, 134(3), e716-e722. https://doi.org/10. 1542/peds.2013-4021.

${ }^{\star}$ Przybylski, A. K., Weinstein, N., \& Murayama, K. (2017). Internet gaming disorder: Investigating the clinical relevance of a new phenomenon. American Journal of Psychiatry 174(3), 230-236. https://doi.org/10.1176/appi.ajp.2016.16020224.

\#Quandt, T. (2017). Stepping back to advance: Why IGD needs an intensified debate instead of a consensus. Journal of Behavioral Addictions, 6(2), 121-123. https://doi.org/10.1556/2006.6.2017. 014.

*Rasmussen, M., Meilstrup, C. R., Bendtsen, P., Pedersen, T. P., Nielsen, L., Madsen, K. R., et al. (2015). Perceived problems with computer gaming and Internet use are associated with poorer social relations in adolescence. International Journal of Public Health, 60(2), 179-188. https://doi.org/10.1007/s00038014-0633-z.

${ }^{\star}$ Rehbein, F., Kliem, S., Baier, D., Mößle, T., \& Petry, N. M. (2015a). Prevalence of internet gaming disorder in German adolescents: Diagnostic contribution of the nine DSM- 5 criteria in a statewide representative sample. Addiction, 110(5), 842-851. https:// doi.org/10.1111/add.12849.

${ }^{\star}$ Rehbein, F., Kliem, S., Baier, D., Mößle, T., \& Petry, N. M. (2015b). Systematic validation of internet gaming disorder criteria needs to start somewhere: A reply to Kardefelt-Winther. Addiction, 110(8), 1360-1362. https://doi.org/10.1111/add.12995.

${ }^{\star}$ Rho, M. J., Lee, H., Lee, T. H., Cho, H., Jung, D. J., Kim, D. J., et al. (2017). Risk factors for internet gaming disorder: Psychological factors and internet gaming characteristics. International 
Journal of Environmental Research and Public Health, 15(1). https://doi.org/10.3390/ijerph15010040.

${ }^{\star}$ Rikkers, W., Lawrence, D., Hafekost, J., \& Zubrick, S. R. (2016). Internet use and electronic gaming by children and adolescents with emotional and behavioural problems in Australia - Results from the second Child and Adolescent Survey of Mental Health and Wellbeing. BioMed Central Public Health, 16, 399. https:// doi.org/10.1186/s12889-016-3058-1.

*van Rooij, A. J., Ferguson, C. J., Colder Carras, M., KardefeltWinther, D., Shi, J., Aarseth, E., et al. (2018). A weak scientific basis for gaming disorder: Let us err on the side of caution. Journal of Behavioral Addictions, 7(1), 1-9. https://doi.org/10. 1556/2006.7.2018.19.

\#van Rooij, A. J., \& Kardefelt-Winther, D. (2017). Lost in the chaos: Flawed literature should not generate new disorders. Journal of Behavioral Addictions, 6(2), 128-132. https://doi.org/10.1556/ 2006.6.2017.015.

\#van Rooij, A. J., \& Prause, N. (2014). A critical review of "Internet addiction" criteria with suggestions for the future. Journal of Behavioral Addictions, 3(4), 203-213. https://doi.org/10.1556/ JBA.3.2014.4.1.

*van Rooij, A. J., Schoenmakers, T. M., \& van de Mheen, D. (2017). Clinical validation of the C-VAT 2.0 assessment tool for gaming disorder: A sensitivity analysis of the proposed DSM-5 criteria and the clinical characteristics of young patients with 'video game addiction'. Addictive Behaviors, 64, 269-274. https://doi.org/10.1016/j.addbeh.2015.10.018.

${ }^{\star}$ Rumpf, H. J., Achab, S., Billieux, J., Bowden-Jones, H., Carragher, N., Demetrovics, Z., et al. (2018). Including gaming disorder in the ICD-11: The need to do so from a clinical and public health perspective. Journal of Behavioral Addictions, 7(3), 556-561. https://doi.org/10.1556/2006.7.2018.59.

${ }^{*}$ Ryu, H., Lee, J. Y., Choi, A., Park, S., Kim, D. J., \& Choi, J. S. (2018). The relationship between impulsivity and internet gaming disorder in young adults: Mediating effects of interpersonal relationships and depression. International Journal of Environmental Research and Public Health, 15(3). https://doi. org/10.3390/ijerph15030458.

${ }^{\star}$ Saunders, J. B., Hao, W., Long, J., King, D. L., Mann, K., FauthBühler, M., et al. (2017). Gaming disorder: Its delineation as an important condition for diagnosis, management, and prevention. Journal of Behavioral Addictions, 6(3), 271-279. https:// doi.org/10.1556/2006.6.2017.039.

*Schivinski, B., Brzozowska-Woś, M., Buchanan, E. M., Griffiths, M. D., \& Pontes, H. M. (2018). Psychometric assessment of the internet gaming disorder diagnostic criteria: An item response theory study. Addictive Behaviors Reports, 8, 176-184. https:// doi.org/10.1016/j.abrep.2018.06.004.

*Shadloo, B., Farnam, R., Amin-Esmaeili, M., Hamzehzadeh, M., Rafiemanesh, H., Jobehdar, M. M., et al. (2017). Inclusion of gaming disorder in the diagnostic classifications and promotion of public health response. Journal of Behavioral Addictions, 6(3), 310-312. https://doi.org/10.1556/2006.6.2017.048.

${ }^{*}$ Sigerson, L., Li, A. Y., Cheung, M. W., Luk, J. W., \& Cheng, C. (2017). Psychometric properties of the Chinese internet gaming disorder scale. Addictive Behaviors, 74, 20-26. https://doi.org/ 10.1016/j.addbeh.2017.05.031.
*Starcevic, V. (2017). Internet gaming disorder: Inadequate diagnostic criteria wrapped in a constraining conceptual model. Journal of Behavioral Addictions, 6(2), 110-113. https://doi.org/ 10.1556/2006.6.2017.012.

${ }^{\star}$ Stubblefield, S., Datto, G., Phan, T. T., Werk, L. N., Stackpole, K., Siegel, R., et al. (2017). Problem video gaming among children enrolled in tertiary weight management programs. Cyberpsychology, Behavior, and Social Networking, 20(2), 109-116. https://doi.org/10.1089/cyber.2016.0386.

${ }^{\star}$ Subramaniam, M. (2014). Re-thinking internet gaming: From recreation to addiction. Addiction, 109(9), 1407-1408. https:// doi.org/10.1111/add.12534.

*Subramaniam, M., Chua, B. Y., Abdin, E., Pang, S., Satghare, P., Vaingankar, J. A., et al. (2016). Prevalence and correlates of internet gaming problem among internet users: Results from an internet survey. Annals Academy of Medicine Singapore, 45(5), 174-183.

\#Sugaya, N., Shirasaka, T., Takahashi, K., \& Kanda, H. (2019). Biopsychosocial factors of children and adolescents with internet gaming disorder: A systematic review. BioPsychoSocial Medicine, 13, 3. https://doi.org/10.1186/s13030-019-0144-5. eCollection 2019.

${ }^{\star}$ Tian, M., Chen, Q., Zhang, Y., Du, F., Hou, H., Chao, F., et al. (2014). PET imaging reveals brain functional changes in internet gaming disorder. European Journal of Nuclear Medicine and Molecular Imaging, 41(7), 1388-1397. https://doi.org/ 10.1007/s00259-014-2708-8.

${ }^{*}$ Vadlin, S., Åslund, C., Rehn, M., \& Nilsson, K. W. (2015). Psychometric evaluation of the adolescent and parent versions of the gaming addiction identification test (GAIT). Scandinavian Journal of Psychology, 56(6), 726-735. https://doi.org/10.1111/ sjop.12250.

Verdejo-Garcia, A., Chong, T. T., Stout, J. C., Yucel, M., \& London, E. D. (2018). Stages of dysfunctional decision-making in addiction. Pharmacology, Biochemistry, and Behavior, 164, 99105. https://doi.org/10.1016/j.pbb.2017.02.003.

Volkow, N. D., Wang, G.-J., Fowler, J. S., Tomasi, D., Telang, F., \& Baler, R. (2010). Addiction: Decreased reward sensitivity and increased expectation sensitivity conspire to overwhelm the brain's control circuit. BioEssays: News and Reviews in Molecular, Cellular and Developmental Biology, 32(9), 748-755. https://doi.org/10.1002/bies.201000042.

${ }^{\star}$ Wang, Y., Hu, Y., Xu, J., Zhou, H., Lin, X., Du, X., et al. (2017). Dysfunctional prefrontal function is associated with impulsivity in people with internet gaming disorder during a delay discounting task. Frontiers in Psychiatry, 8, 287. https://doi.org/10. 3389/fpsyt.2017.00287.

${ }^{\star}$ Wang, C. Y., Wu, Y. C., Su, C. H., Lin, P. C., Ko, C. H., \& Yen, J. Y. (2017). Association between Internet gaming disorder and generalized anxiety disorder. Journal of Behavioral Addictions, 6(4), 564-571. https://doi.org/10.1556/2006.6.2017.088.

Wartberg, L., Kriston, L., Zieglmeier, M., Lincoln, T., \& Kammerl, R. (2019). A longitudinal study on psychosocial causes and consequences of Internet gaming disorder in adolescence. Psychological Medicine, 49(2), 287-294. https://doi.org/10.1017/ S003329171800082X.

We PC. (2019, August 9). 2016 recorded number of video gamers in millions (by region). Retrieved from https://www.wepc.com/ 
wp-content/uploads/2018/05/121-2016-recorded-number-ofvideo-gamers-in-millions-by-region.jpg.

Weinstein, A. M. (2017). An update overview on brain imaging studies of internet gaming disorder. Frontiers in Psychiatry, 8, 185. https://doi.org/10.3389/fpsyt.2017.00185.

*Weinstein, N., Przybylski, A. K., \& Murayama, K. (2017). A prospective study of the motivational and health dynamics of Internet Gaming Disorder. Peer J, 5, e3838. https://doi.org/10. 7717/peerj.3838.

Wichstrom, L., Stenseng, F., Belsky, J., von Soest, T., \& Hygen, B. W. (2019). Symptoms of internet gaming disorder in youth: Predictors and comorbidity. Journal of Abnormal Child Psychology, 47(1), 71-83. https://doi.org/10.1007/s10802-018-0422-x.

${ }^{\star}$ Wong, I. L., \& Lam, M. P. (2016). Gaming behavior and addiction among Hong Kong adolescents. Asian Journal of Gambling Issues and Public Health, 6(1), 6. https://doi.org/10.1186/ s40405-016-0016-x.

World Health Organization. (2019). The 11th revision of the international classification of diseases. Geneva: WHO.

Wood, R. T., \& Griffiths, M. D. (2007). Time loss whilst playing video games: Is there a relationship to addictive behaviours? International Journal of Mental Health and Addiction, 5(2), 141-149. https://doi.org/10.1007/s11469-006-9048-2.

\#Yao, Y. W., Potenza, M. N., \& Zhang, J. T. (2017). Internet gaming disorder within the DSM-5 framework and with an eye toward ICD-11. American Journal of Psychiatry, 174(5), 486-487. https://doi.org/10.1176/appi.ajp.2017.16121346.

${ }^{\star}$ Yen, J. Y., Liu, T. L., Wang, P. W., Chen, C. S., Yen, C. F., \& Ko, C. H. (2017). Association between Internet gaming disorder and adult attention deficit and hyperactivity disorder and their correlates: Impulsivity and hostility. Addictive Behaviors, 64, 308-313. https://doi.org/10.1016/j.addbeh.2016.04. 024.

*Yen, J. Y., Yeh, Y. C., Wang, P. W., Liu, T. L., Chen, Y. Y., \& Ko, C. H. (2017). Emotional regulation in young adults with internet gaming disorder. International Journal of Environmental Research and Public Health, 15(1). https://doi.org/10.3390/ijerph15010030.

*Young, K. S., \& Brand, M. (2017). Merging theoretical models and therapy approaches in the context of internet gaming disorder: A personal perspective. Frontiers in Psychology, 8, 1853. https:// doi.org/10.3389/fpsyg.2017.01853.

${ }^{*}$ Yu, H., \& Cho, J. (2016). Prevalence of internet gaming disorder among Korean adolescents and associations with non-psychotic psychological symptoms, and physical aggression. American Journal of Health Behavior, 40(6), 705-716. https://doi.org/10. 5993/ajhb.40.6.3.

${ }^{\star}$ Yu, S., Mao, S., \& Wu, A. M. S. (2018). The interplay among stress, frustration tolerance, mindfulness, and social support in Internet gaming disorder symptoms among Chinese working adults. Asia-Pacific Psychiatry, 10(4), e12319. https://doi.org/10. 1111/appy.12319.

*Zajac, K., Ginley, M. K., Chang, R., \& Petry, N. M. (2017). Treatments for internet gaming disorder and internet addiction: A systematic review. Psychology of Addictive Behaviors: Journal of the Society of Psychologists in Addictive Behaviors, 31(8), 979-994. https://doi.org/10.1037/adb0000315.

Zendle, D., Meyer, R., \& Over, H. (2019). Adolescents and loot boxes: Links with problem gambling and motivations for purchase. Royal Society Open Science, 6(6), 190049. https://doi.org/ 10.1098/rsos.190049. 